\title{
EL MINISTERIO DE LA ENSEÑANZA EN EL EDUCADOR CRISTIANO LAICO Y SU FUNCIÓN EN LA ESCUELA CONTEMPORÁNEA
}

\author{
Juan Antonio Nureña Prado* \\ Pontificia Universidad Lateranense
}

Resumen: El objetivo de este trabajo es revalorar el papel ministerial de la educación a través del educador cristiano laico. Para ello se explicará el concepto de "ministerio» en un sentido amplio y en un sentido teológico, explicaremos los diversos ministerios laicales en la Iglesia, entre ellos el de la educación y analizaremos los diversos documentos magisteriales. Asimismo, estudiaremos la vocación, las funciones, la identidad y las condiciones para un verdadero ministerio del educador cristiano laico.

Palabras Clave: laico, educación, vocación, obra misionera, escuela católica.

Aвstract: The goal of this work is to value the secular Christian's ministerial role. For this, the concept of «ministry» will be explained both in a wide and theological sense, the different secular ministries in the Church will be dealt with and various magisterial documents will be analyzed. In the same way, we will study the vocation, functions, identity and the conditions for a genuine ministry of the secular educator.

KeY words: secular, education, vocation, missionary deed, Catholic school.

* R. P. Juan Antonio Nureña Prado estudió Filosofía y Teología en la Facultad de Teología Pontificia y Civil de Lima. Ha ejercido la docencia en el Seminario Propedéutico «Santísimo Sacramento» y en la Universidad Católica Sedes Sapientiae (Lima), ambas instituciones de la Diócesis de Carabayllo. Actualmente se especializa en Teología Moral en la Pontificia Universidad Lateranense (Roma). 
JUAN ANTONIO NURENAA

\section{EL MINISTERIO DE LA ENSEÑANZA DEL EDUCADOR CRISTIANO LAICO}

$\mathrm{E}$

$n$ el presente, se aprecia que en el ministerio de la enseñanza, se desarrolla en demasía el papel del cristiano laico. En los inicios de la Iglesia, este papel era solo de los sacerdotes; es decir, era solo destinado al ministerio sacerdotal; actualmente, es un papel que ambos desempeñan — laicos y sacerdotes-. Sin embargo, el sentido de esta investigación es darle mayor importancia al papel ministerial del cristiano laico; puesto que en la actualidad la Iglesia, desde el Concilio Vaticano II, ha abierto las puertas de los ministerios a los laicos — agentes fundamentales de la Iglesia—, quienes cada día se esfuerzan en servir más y mejor a la Iglesia, madre y maestra, en este servicio.

Antes de dar inicio al desarrollo del ministerio de la enseñanza del educador cristiano laico, se explicará el concepto de «ministerio»:

a) En sentido amplio, designa la misión global de la Iglesia; es decir, la de ser continuadora de la obra de Cristo.

b) En sentido teológico y propio, el término "ministerio» se divide en dos tipos «ministerios laicales» $\mathrm{y}$ "ministerios instituidos». Los «ministerios laicales» indican servicios precisos, desempeñados por fieles cristianos laicos, estos ministerios son importantes para toda la comunidad. Además, comporta la responsabilidad de dirección, es reconocido por la iglesia local, supone la delegación oficial conferida por los pastores y es asumido en el acto litúrgico. Estos ministerios buscan una correspondencia entre lenguaje y contenido, entre nombre e identidad y entre ellos encontramos los del servicio de la catequesis y la caridad. Estos, son distintos de los «ministerios instituidos», que son servicios especiales — que implican la ordenación sacramental — llamados también «ministerios ordenados»: episcopado, presbiterado y diaconado. 
Por ello, el término «laical» se emplea para diferenciarlo del ministerio «ordenado»; aun así, los ministerios son, para ambos, «ministerios de los fieles o fieles cristianos»; es decir, del cristiano creyente y perteneciente en plenitud a la Iglesia por el bautismo (Cf. Borobio 1999: 14-16).

\section{LOS MINISTERIOS LAICALES EN LA IGLESIA}

Los ministerios laicales en la Iglesia son los diversos servicios que se prestan para la misión de la ésta; entre estos encontramos, entre los más importantes, al ministerio de la Palabra, la comunión, el culto, la caridad, la acogida y la catequesis.

\section{I. LOS FIELES CRISTIANOS LAICOS}

La Iglesia llama fieles cristianos laicos a todos aquellos bautizados, quienes, al recibir los dones de este sacramento, reciben tres funciones: sacerdotal, profética y real. Por medio de estas funciones, son llamados a desempeñar, dentro del Pueblo de Dios, la misión evangelizadora que Él encomendó cumplir en el mundo: «Son fieles cristianos quienes, incorporados a Cristo por el bautismo, se integran en el Pueblo de Dios y, hechos partícipes a su modo por esta razón de la función sacerdotal, profética y real de Cristo, cada uno según su propia condición, son llamados a desempeñar la misión que Dios encomendó cumplir a la Iglesia en el mundo» (Lumen Gentium 1964: 31). Como menciona el Documento de Puebla: «Son hombres de la Iglesia en el corazón del mundo, y hombres del mundo en el corazón de la Iglesia» (III Conferencia Latinoamérica Puebla 1979: 786). 
JUAN ANTONIO NURENAA

\subsection{IMPORTANCIA DE LOS MINISTERIOS LAICALES EN LA IGLESIA}

Según el deseo de Cristo, su importancia radica en el mandato que todos sean servidores de todos; ya lo mencionaba Jesús en el Nuevo Testamento: «El que quiera ser el primero que sea el servidor de todos» (Mc 10, 44); por tanto, la Iglesia se siente llamada al servicio de los fieles; esto también lo decía San Pablo: «Que cada uno con el don que ha recibido que se ponga al servicio de los demás» (Rm 12, 6); en consecuencia, la diaconía es tarea de todos, y lo es desde la ministerialidad propia de la Iglesia. Es decir que es un servicio al que se convoca a todo el Pueblo de Dios, tanto a los individuos y a la comunidad local como a la Iglesia universal (Cf. Borobio 2001: 70).

Asíla Iglesia tiene ministerios porque es ontológicamente ministerial. La ministerialidad de la Iglesia es, por tanto, un constitutivo fundamental del mismo ser eclesial. Por ello, los ministerios, tanto sacerdotal como laical, son importantes en el servicio de la Iglesia. Con respecto a los ministerios laicales, el Concilio Vaticano II les da considerable importancia:

[...] los laicos pueden ser llamados a una colaboración más inmediata con el apostolado de la jerarquía, al igual que aquellos hombres y mujeres que ayudaban al apóstol San Pablo en la evangelización, pues poseen aptitud de ser asumidos por la jerarquía para ciertos cargos eclesiásticos que habrán de desempeñar con una finalidad espiritual. Por consiguiente, ábraseles por doquier el camino para que, conforme a sus posibilidades y según las necesidades de los tiempos, también ellos participen celosamente en la obra salvífica de la Iglesia. (Lumen Gentium 1964: 33)

Uno de los ministerios laicales que la Iglesia tiene es la educación. Como misterio laical, en el orden de la Palabra, el educador cristiano 
está llamado no solo a ejercer la función de educar e ilustrar, cultural o pedagógicamente, sino también a evangelizar e impulsar hacia una autenticidad en la vida cristiana (Cf. Borobio 2001:38).

\section{EL EDUCADOR CRISTIANO LAICO EN LA ESCUELA CRISTIANA CONTEMPORÁNEA}

\section{I. LA VOCACIÓN ESPECÍfica DEL EDUCADOR LAICO EN LA ESCUELA CONTEMPORÁNEA}

Según la exhortación apostólica Christifideles laici del santo Padre Juan Pablo II, también los fieles laicos son llamados personalmente por el Señor, de quien reciben una misión en favor de la Iglesia y del mundo (Cf. Christifideles laici 1988: 2). Una de estas es la de ser educador «por vocación profesional». Por ello, «el educador laico realiza una tarea que encierra una insoslayable profesionalidad, pero no puede reducirse a ésta. Pues esta está enmarcada y asumida en una sobrenatural vocación cristiana. Debe, pues, vivirse como una vocación» (Congregación para la educación católica 1982: 37).

Para el laico católico, ser profesor es una vocación a la que responde desde su condición y dignidad de cristiano. Es una llamada que lo compromete a un particular modo de ser y de vivir: a imagen de Cristo, maestro y modelo de todo educador católico (Comisión episcopal de educación 1988: 70).

\subsection{FunCIONES DEL EDUCADOR CRISTIANO LAico}

Según Borobio (2001: 180), las funciones del educador cristiano laico son las siguientes: 
a) Función humanizadora: implica la tarea de la personalización y la educación en valores, como la educación para la utopía y la esperanza, la educación para la vida social, la educación para la búsqueda y la apertura al misterio y a lo trascendente. Además, el educador cristiano tiene por función realizar la "primera evangelización», aquella que abre las puertas a la conversión y a la verdadera fe. Se trata no solo de formar líderes, sino de «formar hombres». Todo ello parte de un saber: partir de la vida para conducir la vida.

b) Función inculturadora: le corresponde animar la búsqueda del «dialogo entre fe y cultura» y propiciar una educación para la «memoria históricocultural» y para los avances técnico-científicos. En el diálogo entre fe y cultura ha de desear la armonía entre ellas y desarrollar la evangelización de la cultura, que muestra el referente evangélico para un discernimiento de la verdad. Una inculturación de la fe supone la encarnación de esta en nuevas formas culturales: en el saber mediato e informático y en el saber abierto y universal de otros saberes.

c) Función evangelizadora: es el anuncio explícito del evangelio, como nueva noticia, que llama y reclama la conversión verdadera y fundamental. Conduce a anunciar directamente el mensaje que busca la conversión primera y fundamental en el descubrimiento del «tesoro» y de las «perlas escondidas» (cf. Mt 13, 44-46), que son los alumnos. En esta conversión se suscita la experiencia de Dios en el espíritu, se llega a aceptar el modelo único de Cristo, se produce un centralismo en la vida - que se acepta y se vive afectiva y efectivamente- $-\mathrm{y}$ en la pertenencia eclesial a partir de saberse inserto dentro de una comunidad.

d) Función iniciadora: implica la profundización catequética; es decir, la ilustración de la fe, la iniciación a los signos y símbolos, a la oración y a las celebraciones, al encuentro progresivo y a la experiencia comunitaria, a un cambio de vida y a la adopción de un estilo y forma de vivir en el mundo, bajo una pedagogía catecumenal, en un camino que respeta el proceso de 
la persona mediante el acompañamiento permanente.

e) Función eclesial-comunitaria: realiza su labor en la comunidad cristiana, en donde se suscitan y alimentan sentimientos de pertenencia afectiva y efectiva. Incluye también a las familias, que se consideran «comunidades educativas» mediadoras hacia la comunidad cristiana.

f) Función familiar: esta exige la necesaria colaboración entre las familias y la institución educativa, y viceversa. El educador cristiano necesita conocer la situación religiosa de la familia del educando para conocer el proceso religioso de cada individuo. Por otro lado, el educador cristiano cumple una verdadera función familiar. Si es capaz de educar humanamente a las familias, tiene el reto de crear una nueva «cultura familiar»; por ello, debe darse un espacio al tema «familia» en su programa curricular. El aislamiento educativo de las familias conduce a la ineficacia real de la educación cristiana para la vida.

\subsection{IDENTIDAD DEL MINISTERIO DEL EDUCADOR CRISTIANO LAICO}

La identidad que ha de tener el educador cristiano laico, según Borobio (2001: 178), se basa en los siguientes puntos:

a) La dimensión o aspecto de la misión a la que principalmente sirve y se dedica; es decir, a la Palabra. Es esta la que ocupa el centro del educador cristiano laico en todas las dimensiones: pues abarca la evangelización, la pedagogía, la enseñanza y la cultura; pues, por medio de la transmisión oral, se imparten conocimientos y experiencias de fe fundamentales con la finalidad de suscitar la conversión y ayudar al crecimiento de la fe. A su vez, la tarea del educador laico cristiano debe estar en plena relación con los otros ministerios que sirven a la Palabra en la Iglesia: los teólogos, los catequistas, etc. 
b) La base de su misión eclesial debe partir desde los sacramentos de su Iniciación cristiana: bautismo-confirmación, que lo capacita para ser «profeta» y dar testimonio. En el aspecto del educador cristiano laico, este debe tener la vocación de entregarse a la enseñanza desde una visión cristiana. Si se trata de un educador cristiano ordenado, estaríamos ante una calificación sacramental especial; que se orienta, sobre todo, al cumplimiento de su misión.

c) El ámbito en el cual centra su misión y su identidad es el centro educativo. En este lugar, el educador cristiano laico realiza su misión como una «familia especial»; es decir, el educador laico no actúa en solitario, sino en estrecha relación con todos los que participan en este centro. Se trata, por tanto, de una misión compartida.

d) La identidad del educador cristiano laico debe ser, también, la que se abre y se trasmite a la cultura, a la interdisciplinariedad, al diálogo fe-cultura y a la inculturación de la fe o evangelización de la cultura. Así mismo, la capacitación pedagógica del educador lo dispone de modo eficaz para la comunicación y el diálogo con aquellos a quienes quiere trasmitir el mensaje.

e) El educador cristiano laico, además de tener la cualificación doctrinal necesaria, debe descubrir su identidad en su carácter representativo ante aquellos a los que está educando. El actúa no por su cuenta, sino como representante de Cristo, de la Iglesia y de la comunidad cristiana a la que sirve.

$\mathrm{Al}$ exponer estos puntos para una verdadera identidad del educador cristiano laico hemos de considerar importante su aplicación para una misión verdadera y fructífera en la escuela.

Señalamos a continuación, siguiendo al mismo Borobio, las condiciones que ha de tener el educador cristiano laico para el desarrollo de su ministerio en la enseñanza. 


\subsection{CONDiciones PARA UN VERDADERO MINISTERIO DEL EDUCADOR CRISTIANO LAICO}

Según Borobio (2001: 179), las condiciones para un verdadero ministerio del educador cristiano laico ha de distinguirse claramente entre:

a) El simple educador cristiano, es decir, aquel profesor que no aplica su carisma y su vocación en su labor o tarea educativa. Si es un cristiano laico, es probable que la transmisión de la fe y la evangelización queden diluías si no transmite su ministerio laical de enseñanza con amor y responsabilidad.

b) El educador cristiano laico, por ser un fiel cristiano, que pertenece a la Iglesia por su bautismo, desempeña un papel directo con la fe y la religión. Si desea hacer profundizar a todos los educandos en la enseñanza ha de hacerlo en forma cristiana, es decir, ha de educar teniendo un verdadero ministerio que se realice en torno al servicio de la Palabra; esto es, un determinado estatuto y posición dentro de la Iglesia que enseña en la verdad.

Estas condiciones nos ayudarán a conocer cuál es el camino que debemos de tomar para el desarrollo verdadero del ministerio de la enseñanza y su función en la escuela.

3.5. Doctrina Del Ministerio del educador laico desde el Concilio VATICANO II

A continuación, pasamos a desarrollar la importancia del ministerio de la enseñanza en el educador laico desde el Concilio Vaticano II y sus fuentes magisteriales, consideramos importantes estos criterios que nos ofrece la Iglesia. 
JUAN ANTONIO NUREÑA

\subsubsection{La Declaración Gravissimum educationis}

Esta declaración señala que el ministerio del educador cristiano laico tiene diversas características:

a) Que en este ministerio se coloca al hombre como centro de la labor educativa. Señala la declaración que los profesores tienen la principal responsabilidad en ello y, por eso, se exige de ellos no sólo una formación idónea, a nivel técnico y profesional, sino un testimonio cristiano de vida y de palabra; ya que su misión consiste en un «verdadero apostolado». El reconocimiento de esta vocación exige además unas cualidades especiales intelectuales y afectivas, una preparación esmeradísima y un ánimo abierto a una continua renovación y acomodación (Cf. Gravissimum educationis momentum 1965: 8).

b) Que esta vocación es un verdadero ministerio cuando se trata de la educación moral y religiosa: «Es necesario que la Iglesia cuide de esta educación, [en especial por los sacerdotes y los seglares] que les enseñan la doctrina de la salvación, acomodada a la edad y circunstancias, y les ofrecen ayuda espiritual con medios acomodados a su particular situación» (Cf. Gravissimum educationis momentum 1965: 3).

c) Las funciones que se atribuyen y se solicitan a los maestros son las siguientes: prepararse en este ministerio con especial cuidado y con la pedagogía adecuada, dar testimonio con la forma de vida del auténtico maestro: Cristo, tener en cuenta la diferencia de sexos y sus peculiaridades, atender personalmente a los alumnos con sus consejos y su amistad. (Cf. Gravissimum educationis momentum 1965: 4).

\subsubsection{El Decreto Apostolicam Actuositatem}

Es el decreto sobre el Apostolado de los laicos. En este se menciona implícitamente la labor del educador cristiano laico como un modo 
de apostolado de la iglesia, que invita a acoger con gozo esta misión y a adaptarse a las nuevas necesidades de los tiempos, nos dice el decreto:

Se ruega encarecidamente en el Señor a todos los laicos que respondan con gozo, con generosidad y prontitud de corazón a la voz de Cristo, que en esta hora invita con más insistencia [...]; recíbanla, pues, con entusiasmo y magnanimidad [...] y, tomando sus cosas como propias (Flp 2, 5), asóciense a su misión salvadora [...], para que, con las diversas formas y modos del único apostolado de la Iglesia, que ha de adaptarse continuamente a las nuevas necesidades de los tiempos, se muestren como cooperadores de ella, trabajando siempre con generosidad en la obra de Dios, teniendo presente que su trabajo no es vano delante del Señor (1Cor 15, 58). (Apostolicam actuositatem 1964: 33)

\subsection{Doctrina DEL MiNisterio del EDUCADOR LAICO DESDE LA EVANGELII} NUNTIANDI

El papa Pablo VI se dirige, con esta exhortación, a aquellos —además de los sacerdotes - que en la comunidad cristiana pueden ejercer ministerios diversos. Entre ellos, nombra también a los catequistas y educadores:

Los seglares, cuya vocación especifica los coloca en el corazón del mundo y a la guía de las más variadas tareas temporales, deben ejercer por lo mismo una forma singular de evangelización [...] el campo propio de su actividad evangelizadora el mundo vasto y complejo de la política, de lo social, de la economía y también de la cultura, de las ciencias y de las artes, de la vida internacional, de 
JUAN ANTONIO NURENAA

los medios de comunicación de masas [...] de la educación de los niños y jóvenes, del trabajo profesional [...]. (Evangelii Nuntiandi 1974: 70)

\subsection{Otros DOCUMENTOS MAgisteriales}

Señalamos a continuación otros documentos magisteriales útiles para conocer la misión del educador cristiano laico.

\subsubsection{La pastoral de la escuela católica}

En el documento La pastoral de la escuela católica se menciona que «El educador [...] es mediador entre la comunidad cristiana y el joven. El ser enviado, representante de la comunidad, va en contra del individualismo, y requiere que el educador tenga la humildad suficiente para reconocerse y actuar como medio entre la comunidad y los destinatarios de su misión»

ळ (Cf. Congregación para la educación católica 1994: 37).

\subsubsection{El laico católico testigo de la fe en la escuela}

Este documento — producto de la Congregación para la Educación católica - señala, en primer lugar, que la vocación del educador es «propia de los laicos» (Congregación para la educación católica 1982: 15). El documento no alude al profesor como un profesional que se limita a comunicar de forma sistemática en la escuela una serie de conocimientos, sino como un educador y formador de hombres.

Su tarea rebasa ampliamente la del simple docente; pero no la excluye. Por eso, requiere de una adecuada preparación profesional. Esta 
es el cimiento humano indispensable sin el cual sería ilusorio intentar cualquier labor educativa. Por tanto, se solicita un adecuado profesionalismo y preparación en todo educador católico para que pueda existir una correcta comunicación de la verdad — rasgo fundamental de su participación peculiar en el oficio profético de Cristo-, que prolongue con su magisterio (Cf. Congregación para la educación católica 1982: 15).

El documento señala, además, que todo educador cristiano laico tiene — en su vocación — «un trabajo de continua proyección social; ya que forma al hombre para su inserción en la sociedad, preparándolo para asumir un compromiso social ordenado, mejorar sus estructuras — conforme con los principios evangélicos - y hacer de la convivencia entre los hombres una relación pacífica, fraterna y comunitaria» (Congregación para la educación católica 1982: 15).

A su vez, el educador cristiano laico está comprometido en la tarea de formar hombres que hagan realidad la «civilización del amor» (Cf. Congregación para la educación católica 1982: 15). El educador cristiano laico tiene la misión de hacer comprender al educando el carácter global propio de la cultura, los aspectos laicales y religiosos de la misma y la aportación personal que le corresponde ofrecer desde su estado de vida.

Además, es aquel que ejercita su ministerio en la Iglesia, viviendo desde la fe su vocación secular en la estructura comunitaria de la escuela con la mayor calidad profesional posible, con una pedagogía de contacto directo y personal con el alumno, en la animación espiritual de la comunidad educativa a la que pertenece y de aquellos estamentos y personas con los que esta se relacione (Cf. Congregación para la educación católica 1982: 24). 
JUAN ANTONIO NURENAA

\subsubsection{Formación integral de la fe dentro del contexto cultural y educativo peruano}

Este último documento que se presenta es un escrito de la Conferencia Episcopal Peruana del año 1982. Presenta un amplio diagnóstico de la educación en el Perú y de la acción de la Iglesia en este campo. Indica que el «Episcopado Peruano ha demostrado gran interés y preocupación por la educación y la cultura en nuestro medio» (Conferencia Episcopal Peruana 1982: 25).

Dentro del contexto educativo en el Perú, país rico en diversidad de razas y cultura, señalamos que «la educación en la cultura es el ámbito prioritario de la evangelización» y, más aun en la educación cristiana; en este marco, se debe considerar la «acción educativa» (Cf. García Quesada 1992: 45). En cuanto a la educación católica, García Quesada, resalta su necesario carácter cristocéntrico; por tanto, en la formación del alumno, se debe buscar «alcanzar aquel tipo de hombre que Dios quiso cuando lo creó a su imagen y semejanza [...] un hombre inteligente y libre, personal y comunitario, que reproduciendo en sí mismo la imagen de Cristo, crece día a día en humanidad y personalización» (García Quesada 1992: 51).

Con respecto a los educadores, se les recuerda su «vocación apostólica» (García Quesada 1992: 167), y se destaca su testimonio personal; por ello, deben seguir un proceso constante de conversión. Así mismo, se debe formar en los criterios evangélicos que le ayuden a discernir los valores culturales y a profundizar en la relación del hombre, como persona, consigo mismo; en la relación del hombre, como señor y administrador, con el mundo; en la relación del hombre, como hermano, con los hombres, y en la relación del hombre, como hijo, con Dios (Cf. García Quesada 1992: 167). 


\section{APOYO DE LA IGLESIA AL EDUCADOR CRISTIANO LAICO}

\section{I. TOMA DE CONCIENCIA DE LA IGLESIA DE LA NECESIDAD DE LA FORMACIÓN CRISTIANA DEL EDUCADOR LAICO}

En la actualidad, se percibe el peligro de dejar al educador cristiano laico en el último lugar —en su formación en el ámbito eclesial— por dificultades sociales y económicas; percibimos sobretodo: la pluralidad ideológica de los distintos centros de formación profesional del profesorado, por la pérdida del sentido y de la increencia, por la búsqueda de la satisfacción inmediata y por el rechazo de lo que significa el sacrificio y compromiso. En efecto, esto ha hecho que los educadores laicos cristianos, sobretodo católicos, pierdan de vista la responsabilidad en su formación profesional, sobre todo en su formación religiosa, - $\tan$ necesaria para constituirse en verdaderos testigos de su fe en Cristo dentro del espacio vital personal como profesional-. Es necesario, por eso, iniciar un camino de renovación, concientizando — de forma personal- a cada uno de los educadores cristianos laicos en la búsqueda de una formación profesional y religiosa permanentes. El documento El laico católico testigo de la fe en la escuela nos recuerda — citando al Concilio Vaticano II en la Declaración Gravissimum educationis momentum:

[...] requerir educadores con una personalidad espiritual madura, que sepan expresarse en una profunda vida cristiana, para ello es necesario una profunda preparación diligentísima» [...] «Esta vocación — dice el Concilio Vaticano II refiriéndose a los educadores - exige [...] una preparación diligentísima» [....] «Prepárense (los profesores) con especial cuidado de suerte que posean una ciencia, lo mismo profana que religiosa, garantizada con los debidos títulos, y se enriquezcan, a 
tono con los avances del progreso, en el arte de educar a la juventud. (Congregación para la educación católica 1982: 60)

El texto señala que los educadores poseen una carencia notable en el aspecto religioso, lo que origina que no se perfeccione su formación inicial como lo hace en el orden cultural y profesional (Cf. Congregación para la educación católica 1982: 60). El documento también indica que todo educador laico, católico, tiene que vivir su tarea educativa como medio fundamental de santificación personal y de apostolado (Cf. Congregación para la educación católica 1982: 61). Asimismo, el documento manifiesta que todo educador laico, católico, debe tener conciencia viva de la necesidad de esta formación religiosa de la cual depende su apostolado y el buen ejercicio de su tarea profesional como educador (Cf. Congregación para la educación católica 1982: 63).

Por último, señala el documento, que el educador laico, católico, necesita de la ayuda de su propia comunidad: la Iglesia. Así, los obispos, los sacerdotes, los religiosos y religiosas, los movimientos y las asociaciones educativas laicas

católicas deben, como compromiso eclesial irrenunciable, ayudar a los educadores laicos, católicos, a adquirir plena conciencia de sus necesidades personales en el campo de la formación, y deben estimularlos para entregarse más enteramente al compromiso social que tal formación exige (Cf. Congregación para la educación católica 1982: 73).

\subsection{ForMACIÓN PROFESIONAL Y RELIGIOSA}

En el mismo documento de la congregación para la educación católica, El laico católico testigo de la fe en la escuela, se menciona que es necesario que la Iglesia fomente la formación del profesorado en centros de formación profesional católica; ya que, en la actualidad, se observa que el mundo está invadido de 
un pluralismo ideológico, que abarca todas las esferas del saber humano. Esto provoca que el futuro educador se desvíe de su deseo de lograr una síntesis clara entre fe y cultura y, también, que los elementos cristianos queden incompatibles. La educación, en el aspecto religioso, «tiene que acompañar y complementar su formación profesional estando a la altura de su fe de hombre adulto, de su cultura humana y de su vocación laical específica». En efecto, la formación religiosa debe estar orientada a la santificación personal y al apostolado elementos inseparables, a su vez, de la vocación cristiana (Cf. Congregación para la educación católica 1982: 72).

La formación para el apostolado «supone una cierta integración humana acomodada al carácter y a las cualidades de uno» y requiere «además de la formación espiritual [...] una sólida instrucción doctrinal, es decir, teológica, ética, filosófica». No puede olvidarse tampoco, en el caso del educador, de la adecuada formación en la enseñanza social de la Iglesia, que es «parte integrante de la concepción cristiana de la vida» y ayuda a mantener intensamente viva la indispensable «sensibilidad social» (Congregación para la educación católica 1982: 65). Lo mismo hemos de señalar en la formación de los educadores no católicos que son por su bautismo, en validez sacramental, fieles cristianos.

\subsection{ACtUalizaCión Y FORMaCión PERMANENTE}

Los avances rápidos y profundos que se producen en la realidad y los intentos de comprender mejor la naturaleza del hombre exigen de todo educador incluyendo al educador laico cristiano- que encuentre una nueva vitalidad para poder desarrollar y brindar al mundo una educación acorde con el tiempo presente. Con este tipo de educación, la actualización y formación permanentes alcanzarán los rasgos requeridos para todo educador cristiano: actualización en sus propias actitudes personales, en los contenidos de las materias que se imparten 
y en los métodos pedagógicos que utiliza (Cf. Sánchez Gutiérrez 2000: 53). Lo mismo nos lo señala el documento: El laico católico testigo de la fe en la escuela «Recuérdese que la vocación de educador requiere «una continua prontitud para renovarse y adaptarse» (Congregación para la educación católica 1982: 68).

Esta preparación, actualización y formación permanentes no sólo debe afectar «a la formación profesional, sino también a la religiosa y, en general, el enriquecimiento de toda la personalidad, pues la Iglesia tiene que adaptar constantemente su misión pastoral a las circunstancias de los hombres de cada época, en orden de hacerles llegar de manera comprensible y apropiada a su condición, el mensaje cristiano» (Congregación para la educación católica 1982: 64). Así también, «su renuncia a la formación permanente en todo su campo humano, profesional y religioso lo colocarían al margen de ese mundo que es, precisamente, el que tiene que ir llevando hacia el Evangelio» (Congregación para la educación católica 1982: 70).

\subsection{Apoyo de la Iglesia en la fe, la palabra y la vida sacramental}

Los problemas económicos y sociales tienden, muchas veces, a desmotivar al educador laico cristiano, haciendo que este pierda su fe y que no se esfuerce en la enseñanza del Evangelio. Es una gran responsabilidad de la Iglesia - y de su comunidad - fomentar este apoyo desde la fe, la Palabra y la vida sacramental, esto también nos lo señala el documento: El laico católico testigo de la fe en la escuela: «En la fe hallará con seguridad la humildad, la esperanza y la caridad que necesita para perseverar en su vocación» (Congregación para la educación católica 1997: 75). Por otro lado, se asume lo siguiente:

Todo educador precisa de humildad para reconocer sus limitaciones, sus errores, la necesidad de constante superación y la constatación 
de que el ideal que persigue le desbordará siempre. Precisa también de una firme esperanza, porque nunca puede llegar a percibir en plenitud los frutos de la tarea que realiza con sus alumnos. Y necesita, en fin una permanente y creciente caridad que ame siempre en sus alumnos al hombre hecho a imagen y semejanza de Dios y elevado a hijo suyo por la redención de Jesucristo. (Congregación para la educación católica 1982: 72)

Ahora bien, esa fe humilde, esa esperanza y esa caridad, reciben la ayuda de la Iglesia a través de la Palabra, de la vida sacramental y de la oración de todo el Pueblo de Dios. Porque «la Palabra le dice y le recuerda al educador la inmensa grandeza de su identidad y su tarea, la vida sacramental le da la fuerza para vivirla y le reconforta cuando falla y la oración de toda la Iglesia presenta ante Dios por él y con él, en la seguridad de una respuesta prometida por Jesucristo, lo que su corazón desea y pide y hasta aquello que no alcanza a desear y pedir» (Congregación para la educación católica 1982: 72).

Finalmente, los obispos latinoamericanos expresaron en Santo Domingo lo siguiente: «Debemos promover la formación permanente de los educadores laicos en lo concerniente al crecimiento de su fe y la capacidad de comunicarla como verdadera sabiduría, especialmente en la educación católica» (Cf. IV Conferencia Episcopal Latinoamericana Santo Domingo, 1992: 262).

Y en Aparecida: «Destacamos que la formación de los laicos y laicas debe contribuir, ante todo, a una actuación como discípulos misioneros en el mundo, en la perspectiva del diálogo y de la transformación de la sociedad. Es urgente una formación específica para que puedan tener una incidencia significativa en los diferentes campos, sobre todo en [...], la cultura, de las ciencias y de las artes, [...] y de otras realidades abiertas a la evangelización» (Cf. V Conferencia Episcopal Latinoamericana Aparecida 2007: 283). 
JUAN ANTONIO NURENAA

\section{CONCLUSIONES}

1. Promover y hacer conocer, sobre todo hacer valorar el papel ministerial del educador cristiano laico, como papel fundamental en y para la formación de las futuras generaciones en la escuela.

2. Buscar comprender y comprometer, desde los diversos documentos magisteriales y eclesiales, el sentido y la labor del educador cristiano laico, para así formar hombres que hagan realidad la «civilización del amor»; hacer comprender al educando la importancia de ser formados en la cultura y en la verdad de la Iglesia.

3. Que el educador cristiano laico desempeñe su vocación en la escuela, con la mayor calidad profesional posible, con una pedagogía de contacto directo y personal con el alumno, y con aquellos estamentos y personas, quienes — desde la comunidad educativa — se relacionan con él.

4. Que se preocupe por la animación espiritual de la comunidad educativa a la que pertenece, y a su vez, de la preocupación por una propia formación permanente continua con un apoyo moral, religioso, espiritual y sacramental de la comunidad educativa y de la comunidad eclesial a la que pertenece. 


\section{BIBLIOGRAFÍA}

Borobio, Dionisio

2001 Misión y ministerios laicales. Salamanca: ed. Sígueme.

1989 Los Ministerios en la comunidad. Barcelona: Centro de Pastoral Litúrgica.

1987 Manual del cristiano comprometido. Madrid: Sociedad de Educación Atenas.

1982 Ministerio sacerdotal. Ministerios laicales. Bilbao: Desclée de Brouwer.

Cardo Franco, Andrés

2011 El educador laico católico, testigo de la fe en la escuela. Lima: Vida y Espiritualidad.

COMISIÓN EPISCOPAL DE EDUCACIÓN

1988 Ser maestro en el Perú hoy. Lima: CEP.

1982 Formación integral de la fe dentro del contexto cultural y educativo peruano. Lima: CEP.

Delors, Jacques

1997 «La educación encierra un tesoro: informe a la Unesco de la comisión internacional para el siglo XXI». En SÁNCHEZ GUTIÉRREZ, Roy Abraham. Misión profética del educador católico laico. Lima: FTPCL.

García Quesada, Alfredo

1992 Educación y nueva evangelización. Lima: ODEC. 
JUAN ANTONIO NURENAA

SÁnchez Gutiérrez, Roy Abraham

2000 Misión profética del educador católico laico. Lima: FTPCL.

\section{DOCUMENTOS MAGISTERIALES}

Documentos del Concilio Vaticano II

Constitución Dogmática Lumen Gentium, Roma, 1964.

Constitución Pastoral Gaudium et Spes, Roma, 1965.

Declaración Gravissimum Educationis Momentum, Roma, 1965.

Decreto Apostolicam actuositatem, Roma, 1964.

Decreto Ad Gentes, Roma, 1965.

\section{Congregaciones}

Congregación para la educación católica

1982 El laico católico, testigo de la fe en la escuela. Roma.

1994 La Pastoral de la Escuela Católica. Madrid.

1997 La Escuela Católica. Roma.

Pontificio consejo para la familia

1983 Carta de los derechos de la familia. Roma.

\section{Conferencias episcopales}

III Conferencia Episcopal Latinoamericana Puebla, 1979.

IV Conferencia Episcopal Latinoamericana Santo Domingo, 1992.

V Conferencia Episcopal Latinoamericana Aparecida, 2007.

Conferencia Episcopal Peruana, Formación integral de la fe dentro del contexto cultural y educativo peruano, 1982. 
EL MINISTERIO DE LA ENSEÑANZA EN EL EDUCADOR CRISTIANO LAICO

\section{PABLO VI}

Encíclica Populorum progressio, 1967.

Exhortación apostólica Evangelii Nuntiandi, 1974.

\section{JUAN PABLO II}

Encíclica Laborem Exercens. Roma: Ediciones Paulinas, 1981.

Exhortación Apostólica post-sinodal Christifideles Laici, 1988.

Carta a la Familias. Roma: Ediciones Paulinas, 1994.

Catecismo de la Iglesia Católica. Roma: CEC, 1993. 